Historic, Archive Document

Do not assume content reflects current scientific knowledge, policies, or practices. 



\section{TO THE TRADE:}

\section{FLORISTS MONEY MAKING GLADSR FL}

The following varieties are, and have been, making money for us and should be profitable for you. We have about 125 more new varieties, In small quantitíes which we will be pleased to answer inquiries on and quote fair prices.

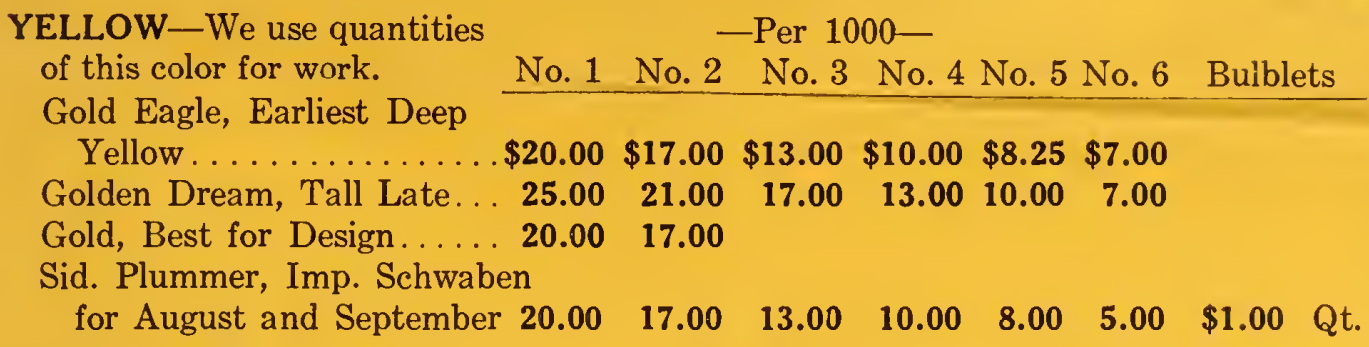

ORANGE-The best retail

color today.

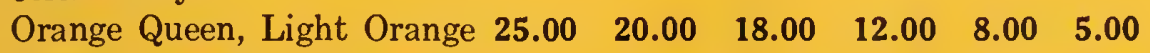

Good alone or with yellow.

$\begin{array}{llllllll}\text { Marnia, Large Bitter-Sweet. } 28.00 & 22.00 & 16.00 & 14.00 & 7.00 & 5.60 & 2.00 & \text { Qt. }\end{array}$ Orange, our best seller.

Ming Toy, Buff Prim. good. $20.00 \quad 17.0015 .00$

Gloriana, Sal. Buff....... $28.00 \quad 24.00 \quad 16.00$

Helen Howard, Bronzy Buff $25.00 \quad 20.00 \quad 15.00 \quad 18.00 \quad 8.00 \quad 5.00$

RED-

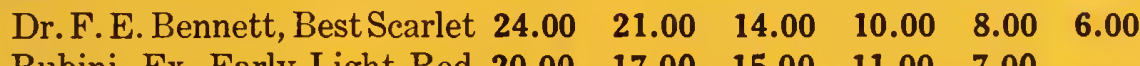

Rubini, Ex. Early Light Red $20.00 \quad 17.00 \quad 15.00 \quad 11.00 \quad 7.00$

Pride of Lancaster, Ruff. Lt.

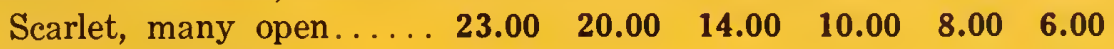

Scarlano, Ruff Deeper

Scarlet............20.00 17.00

$\frac{2}{3}$ Lancaster, $\frac{1}{3}$ Scarlano makes

an extra nice Wreath or Spray

Crimson Glow, Crimson.... $17.00 \quad 14.00$

Groff's Majestic, Crimson. $17.00 \quad 14.00$

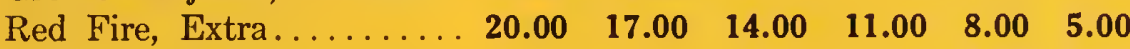

$\begin{array}{lllllll}\text { H. Klanzlieter, extra early . } & 24.00 & 21.00 & 14.00 & 10.00 & 8.00 & 6.00\end{array}$

Dark Velvety Crimson.

\section{WHITE-}

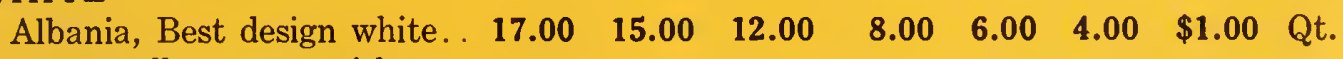

It cuts all summer with us.

Carmen Sylvia, Best Spray

White......................

White Butterfly ............
White prime for Basket or

Bridal Work.

\section{PINK-}

Pendelton...............

Elizabeth Tabor, Extra Early 17.00

$15.00 \quad 12.00$

$\begin{array}{lll}17.00 & 15.00 & 12.00\end{array}$

$\begin{array}{lll}17.00 & 15.00 & 12.00\end{array}$

$\begin{array}{lll}8.00 & 6.00 & 4.00\end{array}$

Lighter than Pendleton.

Best for baskets.

Twilight, Ruf Cream Pink. . 20.00

For late July on.

Prince of Wales, Lt. Salmon 20.00
Good, extra early for July Good, extra
1 st to 15 th.

Los Angeles, Shrimp Pink . . $18.00 \quad 16.00$

Odin, Early Jasper Pink.... $18.00 \quad 16.00$

Giant Nymph, Extra Pink. 20.0017 .00

14.00

14.00

14.00

$8.00 \quad 6.00 \quad 4.00$

1.00 Qt.

For mid season and late large.

W. H. Phipps, Late...... 40.00 Giant Pure Pink.

Longfellow, Midseason . . . $25.00 \quad 18.00$ Tall Pure Pink.

Louvain, Giant Rose Pink. . 50.00

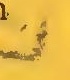


